\title{
Effectiveness of Incorporation Traditional Costumes into Educational Curriculum to Enhance Students' Awareness of Their Heritage
}

\author{
Aisha Hassan Ali Al-Shehri, Maha Abdullah Al Dabbagh \\ King Abdulaziz University, Jeddah, KSA \\ Email: aisha@kku.ed.sa,Maldabag@kau.edu.sa
}

How to cite this paper: Al-Shehri, A. H. A., \& Al Dabbagh, M. A. (2021). Effectiveness of Incorporation Traditional Costumes into Educational Curriculum to Enhance Students' Awareness of Their Heritage. Open Journal of Social Sciences, 9, 14-24. https://doi.org/10.4236/jss.2021.96002

Received: April 11, 2021

Accepted: June 4, 2021

Published: June 7, 2021

Copyright $\odot 2021$ by author(s) and Scientific Research Publishing Inc. This work is licensed under the Creative Commons Attribution International License (CC BY 4.0).

http://creativecommons.org/licenses/by/4.0/

\begin{abstract}
Students need to learn about their cultural costumes and art in general to see how smart and skillful their ancestors were in the past, as this would boost their national identity and link them with glory of the past. They need to be taught the things that strengthen their sense of national belonging, and love of traditional costumes. Therefore, they must be introduced to their authentic heritage in innovative and lovely ways. This paper tries to attract the attention of educators to this fact so that they can effectively guide children to find real truth and knowledge and, at the same time, realize their true essence through tradition. This research examines the effectiveness of introducing traditional costumes to children to enhance their sense of national belonging at childhood stage and seeks to find the best way that may connect our children with their heritage to preserve the national identity. For this purpose, a survey was conducted to measure students' knowledge of their traditional costumes prior to introducing them to a booklet on traditional costumes. After introducing students to a booklet on traditional costumes of the Kingdom of Saudi Arabia, another survey was conducted to examine the effect of the booklet in strengthening their knowledge of traditional costumes and sense of national identity. The researcher has concluded that introducing traditional costumes through educational curriculum would enhance children's knowledge of culture, promote their national identity and strengthen their sense of patriotism.
\end{abstract}

\section{Keywords}

Children, Introductory Booklet, Traditional Costumes, National Identity

\section{Introduction}

Traditional costumes express an identity through costume, which is usually as- 
sociated with a geographic area or a period of time in history. It can also indicate social, marital or religious status. If the costume is used to represent the culture or identity of a specific ethnic group, it is usually known as ethnic costume. Teaching our children their tractional costumes has become a necessity to enhance their national identity.

The formulation and conservation of the cultural identity of a child takes place mostly within the educational process and through the connection of the child to language. Therefore, common and longstanding tradition, constitutes the basis upon which cultural identity is formed, and the best time to build upon such is the preschool years and the first years of primary school (Pashalidis, 2015).

The world considers our children as the most important group of our societies, who must be taken care of during childhood. What children learn at childhood stage is considered the cornerstone for them, as children of the present are men of the future.

The child is an active learner with many fantasies and curious questions. Therefore, they must be guided and educated to have knowledge about their society and its heritage (Al-Bassam et al., 2017). The child has several physiological needs, including the need to have a sense of national belonging, as well as the need for learning, knowledge and understanding. Learning is a basic process in human life, and society will only advance through the experiences of previous generations which should be developed and improved (Shalash, 1996). Therefore, our children must be taught the things that strengthen their sense of national belonging, love of traditional costumes. They must be introduced to their authentic heritage in innovative and lovely ways.

\subsection{Importance of Transferring Traditional Culture to Children}

Traditional costumes, being as cultural heritage and customs, differ from one country and people to another in term of their details, colors, methods of weaving and style of dressing. The issue of adherence to them across different generations is controlled by the general culture and the course of community development. Therefore, we must preserve our heritage and transfer it to our children in order for them to get acquainted with it and become familiar with its importance and beauty (Al-Azhari \& Al-Habsi, 2015).

An exploratory study was made to measure the girl's knowledge of traditional costumes and identify the impact of globalization on our children's understanding of cultural costumes. The results have shown that children are not aware of their traditional costumes. It also emphasized the necessity of introducing our children to the Saudi traditional costumes as a means to enhance their national identity. Therefore, it becomes clear how important it is to transfer popular culture to our children during late childhood, being an important stage in the child's life, because it represents a transition from the early childhood stage to late childhood. Late childhood is the best stage in the child's life through which they can learn various skills. It has unique characteristics that distinguish it from 
precedent childhood stage, in terms of children's interest in others and their social participation and interaction with people. Thus, they will be able to rely on themselves in making their decisions without seeking assistance from the others.

\subsection{Traditional Dress in Saudi Arabia}

The religion and customs of Saudi Arabia dictate not only conservative dress for men and women, but a uniformity of dress unique to most of the Middle East (Sharp, 2014). Traditionally, the different regions of Saudi have had different dress, but since the re-establishment of Saudi rule these have been reserved for festive occasions (i.e. Najd) (Long, 2005). Some of the largest collections of Saudi dress and material include the Art of Heritage and Haifa Faisal collections in Riyadh and the Mansoojat Foundation based in Jeddah.

Examples of Saudi regional dress styles in the AOH collection (Riyadh). From left to right-Najdi bride wearing a heavily embellished voluminous over dress (thawb mugassab), Najdi bride wearing a dafat al-'arus (over dress resembling a man's bisht), Sharqiyah outfit with gold thread (zarri) embroidery in the national emblem and the bukhnuqhead covering, Meccan bridal outfit, bride from Medina, embellished thawb marhadan worn by women in the Harb or Bani Salim tribes (known as "Bedu Mecca") in the rural areas of the Hijaz, heavily embroidered dress in yellow threads worn by Bani Malik women in the rural areas of the Hijaz, heavily embellished dress with flared skirt worn by women in Abha and the highland areas of the South, and embroidered dress worn by women in Wadi Mahram near Ta'if in the Hijaz (Figure 1).

\subsection{Maintaining Heritage through Education}

Maintaining heritage is the responsibility of educational institutions. This can be achieved by innovative methods of education. Advanced professional training is mandatory to teach students their heritage through incorporating it in school curricula (Zimmerli \& Albert, 2010).

Boxtel et al. (2011) defined heritage education is "an approach to teaching and learning that uses material and immaterial heritage as primary instructional resources to increase pupils' understanding of history and culture. Heritage educational challenges in dealing with the past".

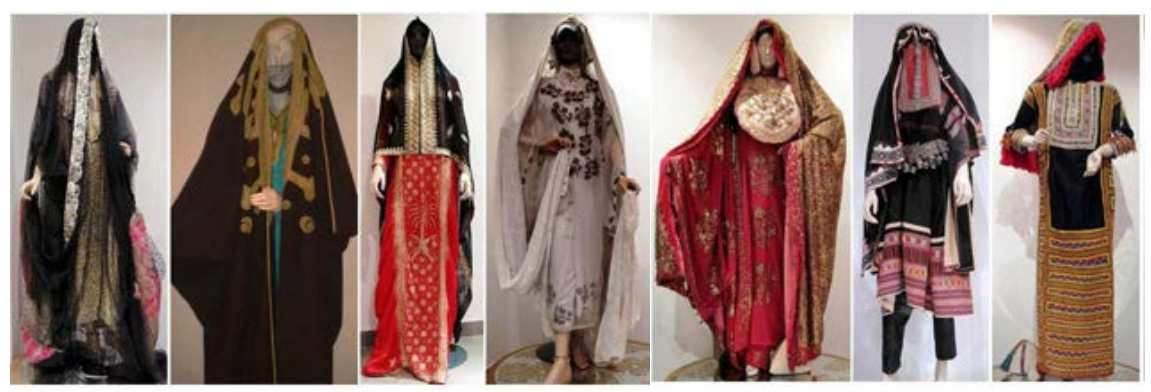

Figure 1. Collections of Saudi traditional costumes. IMAGE CREDITS, Art of Heritage (Riyadh) 2012. 
Heritage education is key to keep generations of students informed about their heritage. World organization such as UNESCO support heritage education and make use of heritage to enhance learning processes of learners (Lakerveld \& Gussen, 2009). Heritage education is a means to boost the learning experience through onsite visitation and appreciation of archaeological resources and what they tell us. The cultural heritage dimension is suggested to be included at all levels of education, not particularly as a core subject but through interdisciplinary actions (Bonnic, 2009).

One of the basic reasons for damage of heritage is the lack of awareness to the public (Shankar \& Swamy, 2013). There is a need to support schools to develop consciousness about the cultural heritage.

\subsection{Cultural Awareness}

Hofstede (1997) defines culture as "the collective programming of the mind that distinguishes the members of one group or category of people from others". Philippe (2003) defines culture as "a group's culture is the set of unique characteristics that distinguishes its members from another group".

Cultural awareness is attained when a person identifies his personal heritage, beliefs, and values in order to identify others' beliefs. The more interaction between different groups is effective, the more the value for cultural awareness enhances (Mfa et al., 2013). What is considered as appropriate in one culture is possible to be inappropriate in another, and then, misunderstandings arise when people communicate (Baird, Jia $\mathrm{Hu}$, \& Reeve, 2011). Students are exposed to new cultures through the communication with others either their classmates, their teachers. So, increasing the cultural awareness can help them embrace (Carter et al., 2016). There is a need to develop curriculum and materials, employ and train efficient instructors (Wang, 2001). Boosting the value of cultural heritage is included in many European curricula. Rigorous cultural engagement makes the individual perceive the world from different perspectives (Villegas \& Lucas, 2002). For this cause, many teacher educators support for cross-cultural experiences to become conditions of teacher education programs (Murry \& Herrera, 1999).

\section{The Research Problem}

Despite the artistic and technical richness of traditional costumes, the researcher found that children were not properly oriented towards traditional heritage. One of the most important recommendations of Al-Bassam's study (Al-Bassam, 2015) has called for communicating traditional heritage to our children, especially as we live in the era of globalization and technology that diminish children's sense of their national identity. Therefore, the research problem can be introduced through the following question:

- How effective an introductory booklet on traditional costumes would be in helping our children acquire knowledge about traditional costumes? 


\section{The Research's Significance}

- Attracts the attention to the importance of introducing traditional costumes to children through school curriculum in order to enhance their sense of national belonging at childhood stage.

- Highlights the importance of connecting children with their heritage to preserve the national identity.

\section{Research Objectives}

- Introduce children to various traditional female costumes in the Kingdom of Saudi Arabia through school curriculum in order for them to have a sense of national belonging and love of their traditional costumes.

\section{Research's Hypotheses}

- Students are not familiar with traditional costumes of their ancestors.

- Introducing students to ancestors' traditional costumes through school curriculum would increase their knowledge of their heritage.

\section{Research Tool}

Two surveys were used to answer the research's hypotheses. The first survey was meant to measure children's awareness of traditional costumes prior to introducing her to a booklet on traditional costumes. The second survey was meant to examine the effect of an educational booklet in strengthening children's knowledge of traditional costumes.

\section{Research Surveys and Procedures}

The first survey included general questions about age and educational grade of the research sample which included 50 children from Jeddah-based preparatory schools.

The majority of research sample were children aged between 6 - 9 years (preoperatory stage, Figure 2), since the focus is to prove that this age category is best stage through which children can be introduced to traditional costumes through a school booklet. Additionally, choosing a sample of several age segments (Figure 3) were meant to measure awareness among students from different school stages in order to confirm that there is a need to introduce traditional costumes to students in early school years, as it was shown that a greater segment of high school and undervest students were unaware of traditional costumes.

First students were asked whether or not they have been ever introduced to traditional costumes. It was shown that majority of students have never been effectively introduced to traditional costumes (Figure 4).

Matching tests, comprised of photos of traditional costumes, were then conducted to measure students' awareness of traditional costumes before introducing the proposed booklet. It was shown that majority of students from different educational stages were not familiar with traditional costumes (Figure 5). 


\section{AGE OF CHILDREN}

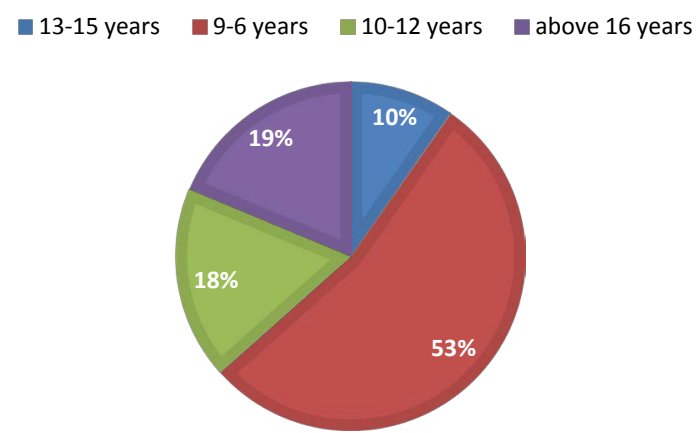

Figure 2. Age of children.

\section{EDUCATIONAL GRADE}

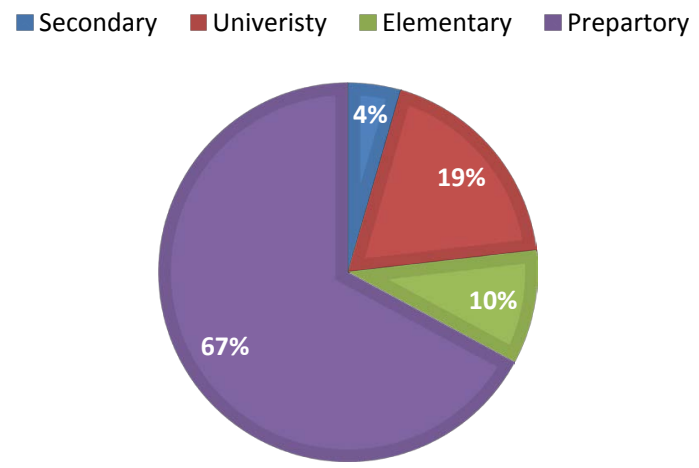

Figure 3. Educational grade of research sample.

- Secondary $\square$ Univeristy $\square$ Elementary $\square$ Prepartory

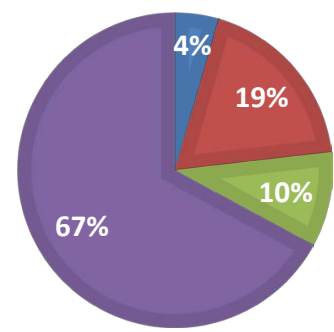

Figure 4. Majority of students have never been.

A mini-booklet, comprised of eight images with details about the region into which the traditional costumes belong, have been introduced to the students. Later, tests were conducted to measure students' familiarity with traditional costumes (Table 1).

\section{Discussion of Results}

By comparing level of students' knowledge on traditional costumes before the introduction of the introductory booklet (pretests) with the results of the posttests, it was remarkably noticed that a majority of students were able to identify 


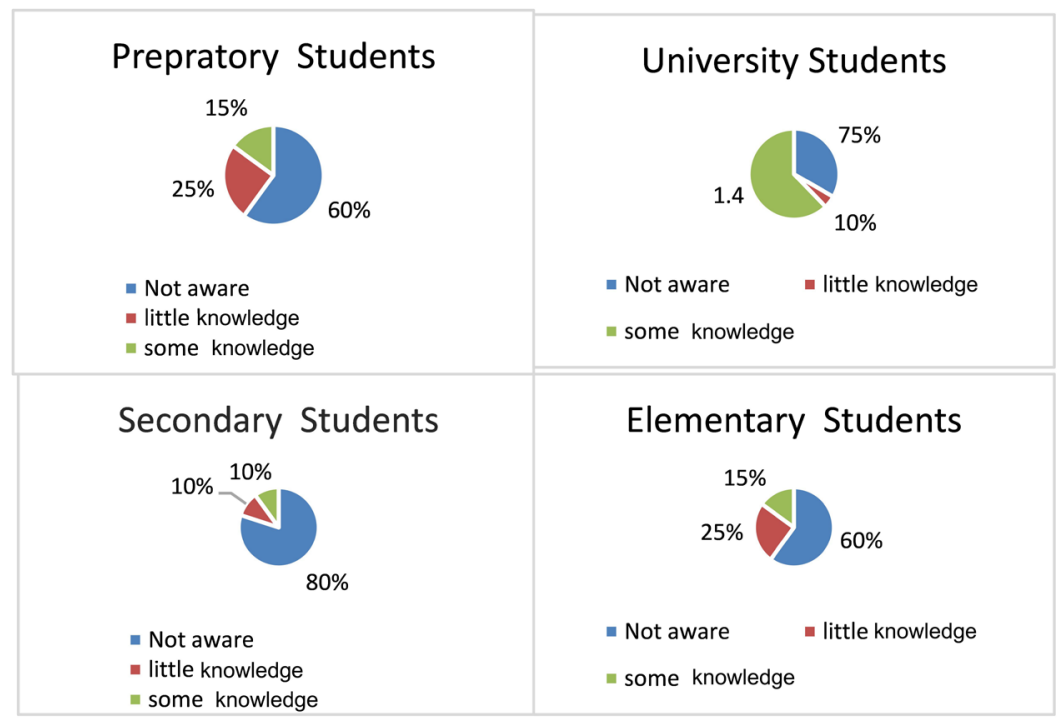

Figure 5. Students' awareness of traditional costumes before introducing the booklet.

Table 1. Tests results after students were introduced to traditional costumes.

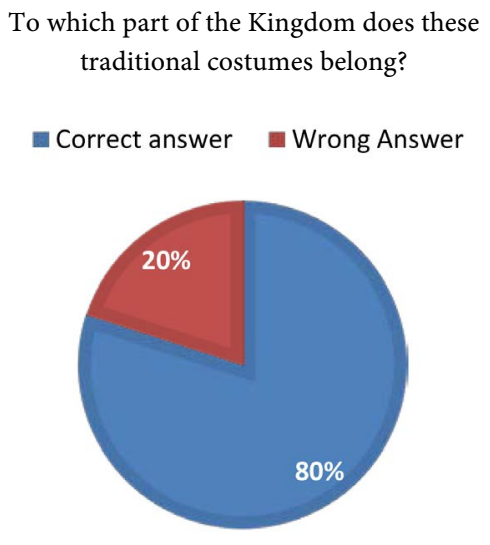

- Correct answer $\quad$ Wrong answer

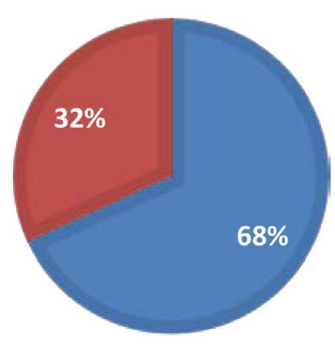

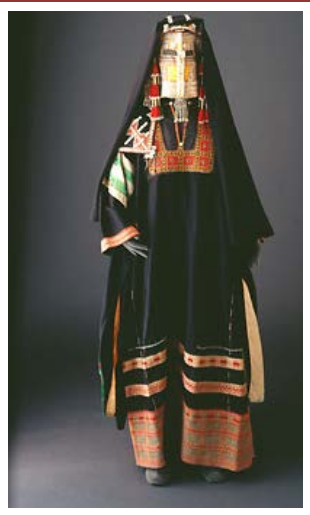

The Sulaym are related to the Harb, and led a semi-settled life near the Red Sea coast as fishermen, traders and herders.

Photo credit:

http://www.mansoojat.org/costume20.html

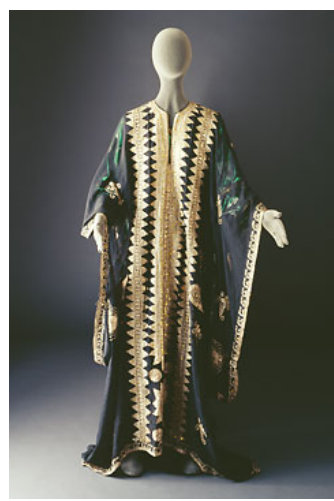

Najd and Central Region thobe in chiffon embroidered with sequins and gold thread.

Photo credit:

http://www.mansoojat.org/costume20.html 


\section{Continued}

\section{Correct answer Wrong answer}

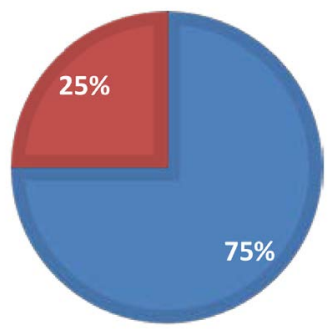

Correct answer Wrong answer

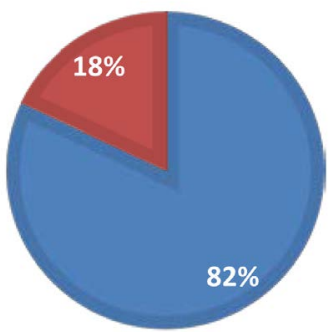

Correct answer $\quad$ Wrong answer

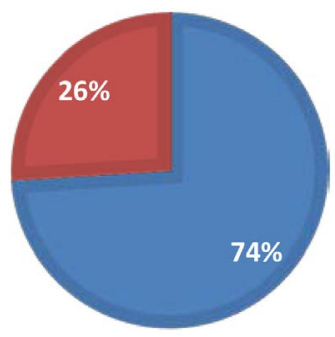

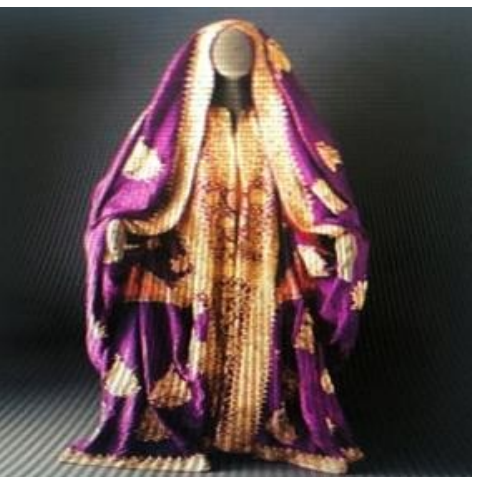

The Bani Sa'd tribe: Costumes, Najd, Central Region and Eastern Region

Photo credit: www.pinterest.com

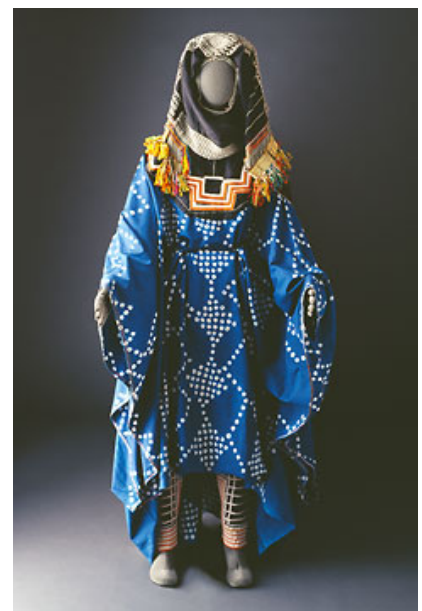

The noble tribe of Hudheyl lives in the Taif area. Hudheyl costumes are made of tie-dyed muslin applied in different patterns.

Photo credit:

http://www.mansoojat.org/costume05.html

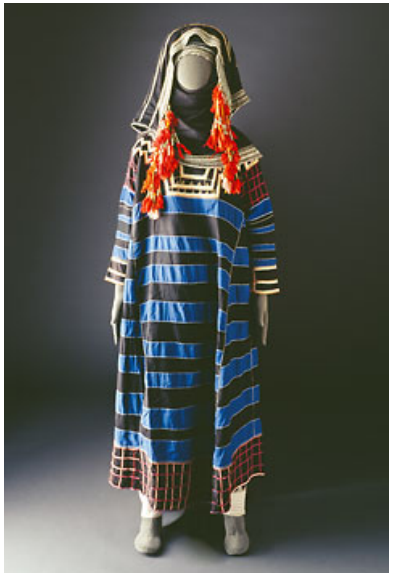

The Thaqeef tribe. Western region

Thaqeef mubaqar thobe from the Shafa area is sewn together in alternating bands.

Photo credit:

http://www.mansoojat.org/costume07.html 


\section{Continued}

Correct answer Wrong answer

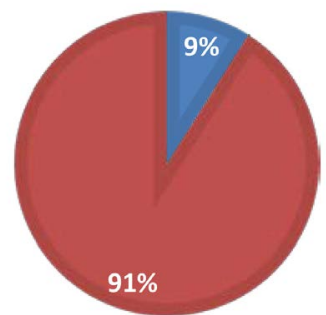

E Correct answer $\quad$ Wrong answer

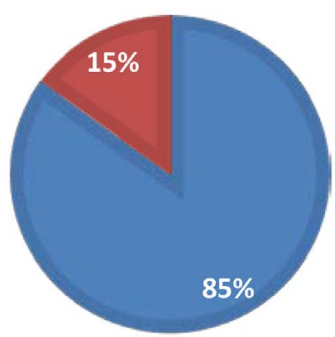

Correct answer Wrong answer

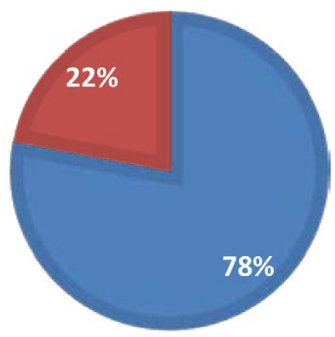

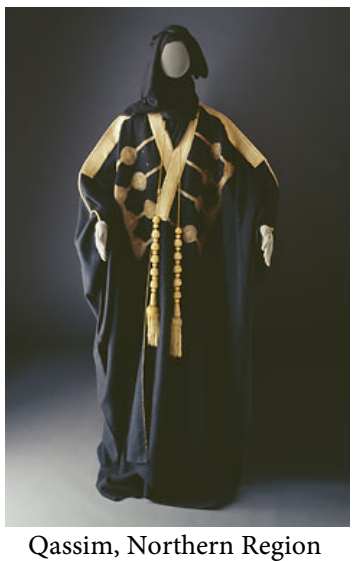

Qassim thick wool woman's aba (cloak) embroidered with gold thread and having elaborate gold thread tassels.

Photo credit:

http://www.mansoojat.org/costume22.html

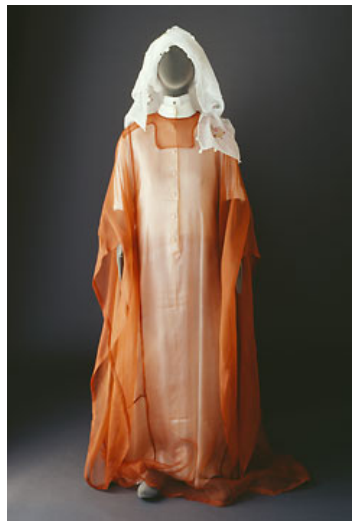

Hijaz, Western Region

Hijaz outfit comprising the inner silk zaboon under the fine organza thobe.

Photo credit:

http://www.mansoojat.org/costume31.html

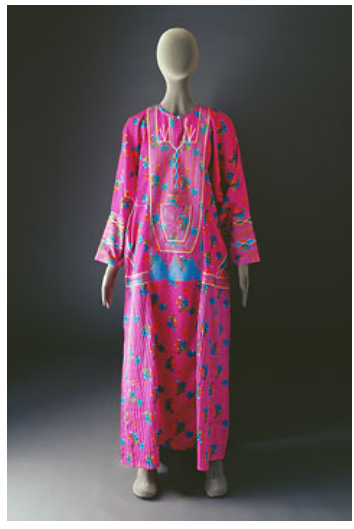

Asir, Southern Region

Asir bright floral printed thobe with the traditional cut and decorative stitching along the front and sides.

Photo credit:

http://www.mansoojat.org/costume15.html 
the region into which the traditional costume belongs after being introduced to the proposed mini-booklet, while at the beginning they were not able to identify them. The research's findings answer the research's two hypotheses that 1) students are not familiar with traditional costumes of their ancestors and 2) introducing children to ancestors' traditional costumes through school curriculum would increase their knowledge of their heritage.

The research's results also augment the Al-Bassam's study (2015) in which he has recommended introducing traditional costumes to our children through education. The results of Qasiri's study (2017) have also shown that rate of students' responses to the question of traditional costumes in the Kingdom's western region was 6\%; a very low rate indicating a decline in children's knowledge of cultural heritage and, hence, the need to introduce them to traditional costumes.

\section{Recommendations}

- Introducing traditional costumes to students through educational curriculum.

- Promoting and conducting academic research important for the understanding of the history and culture of the region, and to raise public awareness for the appreciation of this unique heritage.

- Alerting the media to the importance of raising children's awareness of traditional costumes through TV programs that focus on traditional costumes, in order to enhance children's knowledge of their culture.

\section{Conflicts of Interest}

The authors declare no conflicts of interest regarding the publication of this paper.

\section{References}

Al-Azhari, M., \& Al-Habsi, A. (2015). Traditional Costumes, a National Identity That Resists Globalization.

https://www.albayan.ae/one-world/correspondentssuitcase/2015-04-04-1.2346741

Al-Bassam, L. (2015). Traditional Heritage of Women's Costumes in the Al Sharqiya Region of Saudi Arabia. Journal of the Human Sciences, University of Bahrain, .2, 250-252.

Al-Bassam, L. et al. (2017). Using Children's Literature in Defining Traditional Costumes. Kuwait: Kuwait University-Academic Publication Council.

Baird, K., Jia Hu, K., \& Reeve, R. (2011). The Relationships between Organizational Culture, Total Quality Management Practices and Operational Performance. International Journal of Operations \& Production Management, 31, 789-814. https://doi.org/10.1108/01443571111144850

Bonnic, U. M. (2009). The Human Right to Cultural Heritage-The Faro Convention's Contribution to the Recognition and Safeguarding of This Human Right. In Bonnic (Ed.), Heritage and Beyond (pp. 53-58). Strasbourg: Council of Europe Publishing. https://www.coe.int/t/dg4/cultureheritage/heritage/identities/PatrimoineBD en.pdf

Carter, C. J., Bishop, J., \& Kravits, S. L. (2016). Keys to Success: Cultural Awareness and 
Global Citizenship. London: Pearson Education.

https://www.pearsonhighered.com/program/Carter-Keys-to-Success-Cultural-Awarene ss-and-Global-Citizenship/PGM45559.html

Hofstede, G. (1997). Cultures and Organizations: Software of the Mind. New York, NY: McGrawHill.

Lakerveld, J. V., \& Gussen, I. (2009). Acquiring Key Competences through Heritage Education. Lies Kerkhofs, Bilzen: Landcommanderij Alden Biesen.

http://online.ibc.regione.emilia-romagna.it/I/libri/pdf/Aqueduct EN.pdf

Long (2005). Culture and Customs (pp. 57-59).

Mfa, A. R., Reddy-Linga, S., Kucko, J., \& Prestwood, L. (2013). The Importance of Teaching Cultural Awareness in Design Education: Evidence from Interior Design. Global Journal of Human Social Science Linguistics \& Education, 13, 39-45.

Murry, K., \& Herrera, S. (1999). CLASSIC Impacts: A Qualitative Study of ESL/BLED Programming. Educational Considerations, 26, 11-19.

https://doi.org/10.4148/0146-9282.1345

Pashalidis, G. (2015) Cultural Identity as a Right and as a Threat. The Dialectic of Identity and Ambivalence of Criticism. In C. Konstantopoulos, L. Marantou-Alifanti et al. (Eds.) (p. 80). op cit. (In Greek)

Philippe, R. (2003). Coaching across Cultures. London: Nicholas Brealey Publishing.

Qasri, M. (2017). Methods and Mechanisms of Harmonizing the Heritage Identity and the Risks of Globalization. In The First National Forum: A Reading of Heritage and Identity at a Time of Globalisation.

Shalash, Abd al-R. (1996). The Child's Book: Reality and Perspectives in the Culture of Our Children.

Shankar, B., \& Swamy, C. (2013). Creating Awareness for Heritage Conservation in the City of Mysore: Issues and Policies. International Journal of Modern Engineering Research, 3, 698-703.

Sharp, A. G. (2014). What's a Wahhabi? Net Places, Archived from the Original on March 21

Van Boxtel, C., Klein, S., \& Snoep, E. (2011). Heritage Education Challenges in Dealing with the Past (pp. 9-10). Amsterdam: Erfgoed Nederland.

Villegas, A. M., \& Lucas, T. (2002). Educating Culturally Responsive Teachers: A Coherent Approach. Albany, NY: SUNY Press.

Wang, S. C. (2001). Improving Chinese Language Schools: Issues and Recommendations. In X. Wang (Ed.), A View from Within: A Case Study of Chinese Heritage Community Language Schools in the United States (pp. 63-67). Washington DC: National Foreign Language Center.

Zimmerli, W. C., \& Albert, M. -T. (2010). World Heritage and Cultural Diversity. Cottbus: Druckzone GmbH \& Co. KG. 